\title{
Effects of La Dopant on Nanocluster Size and Optical Band Gap of CdO Films Prepared by Sol-Gel Method
}

\author{
Z.A. Alahmed ${ }^{a, *}$, Z. Serbetçi ${ }^{b}$ And F. Yakuphanoglu ${ }^{c}$ \\ ${ }^{a}$ Department of Physics and Astronomy, College of Science, King Saud University, Riyadh 11451, Saudi Arabia \\ ${ }^{b}$ Department of Chemistry, Bingöl University, Bingöl, Turkey \\ ${ }^{c}$ Department of Physics, Faculty of Science, Firat University, Elazig 23169, Turkey
}

(Received February 20, 2013; in final form March 27, 2013)

\begin{abstract}
The undoped and lanthanum doped cadmium oxide thin films were prepared by sol-gel method. The CdO films were doped with various percentages of La, $0.1,0.5,1$, and 2 at.\%. We have investigated the structural properties of the $\mathrm{CdO}$ films by atomic force microscopy. The obtained results show that both the grain size and the surface roughness of $\mathrm{CdO}$ films reduce with increase of La doping content. Additionally, the result shows a significant decrease of the transmittance in the range of 300 to $500 \mathrm{~nm}$ with increase of La doping level. The optical band gap of $\mathrm{CdO}$ films increases with La doped $\mathrm{CdO}$ films. It was found that the band gaps to be 2.25, 2.36, 2.4, 2.28 , and $2.31 \mathrm{eV}$ for La contents with $0.1,0.5,1$, and 2 at.\% doped CdO, respectively.
\end{abstract}

DOI: $10.12693 /$ APhysPolA.124.125

PACS: 78.20.Ci, 78.67.-n, 81.20.Fw

\section{Introduction}

Cadmium oxide has received considerable attention because of its important properties. It is direct band gap energy with $2.2 \mathrm{eV}$ [1]. Because of its high conductivity with high transparency in the visible region, it has been used in several applications including optoelectronic devices and photovoltaic applications [2-5]. Synthesis of $\mathrm{CdO}$ films with different types of doping elements such as $\mathrm{Al}$ [6, 7], $\mathrm{Cu}$ [8], Ga [9], F [10], Li-Ni [11], Bi [12], $\mathrm{Fe}[13], \mathrm{B}-\mathrm{H}$ [14] confirms the possibility of tuning their material properties to be utilized in new applications in optoelectronic devices and sensors.

Previous reports have showed that the effects of lanthanum doping on the dielectric, electrical and electromechanical properties on different material such as barium titanate $[15,16]$ and zirconium oxide [17]. Dakhel and Ali-Mohamed [18] have studied $\mathrm{CdO}$ films with lanthanum doping. They have prepared 1,5 , and $7 \% \mathrm{La}$ doped CdO films by a spin coater sol-gel technique on amorphous glass and crystalline Si substrates. They have shown that La doping increases the CdO lattice parameter and the optical band gap energy decrease from $2.1 \mathrm{eV}$ to $1.7 \mathrm{eV}$.

In this paper, we investigate both the structural and optical properties for undoped $\mathrm{CdO}$ and La-doped $\mathrm{CdO}$ film with various low percentages of La compared to that in Ref. [18]. Our aim is to improve new nanostructure $\mathrm{CdO}$ films to control their structural and optical properties to be utilized in new applications in optoelectronic devices.

*corresponding author; e-mail: zalahmed@ksu.edu.sa

\section{Experimental details}

The undoped and lanthanum doped cadmium oxide thin films were prepared using the precursors: cadmium acetate dehydrate, lanthanum(III) acetate hydrate, methanol, and monoethanolamine. Firstly, the cadmium acetate dehydrate $\left(\mathrm{Cd}\left(\mathrm{CH}_{3} \mathrm{COO}\right)_{2} \cdot 2 \mathrm{H}_{2} \mathrm{O}\right)$ $(0.5 \mathrm{M})$ was dissolved in methanol for $30 \mathrm{~min}$ at $60^{\circ} \mathrm{C}$ and then, the monoethanolamine was added to this solution [11]. The $\mathrm{CdO}$ films were doped with various atomic percentages $(0.1,0.5,1$, and 2 at.\%) of lanthanum. The La contents were calculated using atomic ratio formula and then, the $\mathrm{CdO}$ films were doped by the calculated atomic ratios of La. The solutions were stirred using a magnetic stirrer for about $30 \mathrm{~min}$. The obtained sols were used for preparation of the $\mathrm{CdO}$ films. The films were grown on microscopy glasses using sol-gel spin coater at $1500 \mathrm{rpm}$ for $30 \mathrm{~s}$ and then, the films were dried at $150^{\circ} \mathrm{C}$ for $10 \mathrm{~min}$ onto a hot plate to evaporate the solvent and remove organic residuals. The prepared $\mathrm{CdO}$ solid films were annealed at $400^{\circ} \mathrm{C}$ for $1 \mathrm{~h}$ in a furnace [11]. The surface morphology properties of the $\mathrm{CdO}$ films were performed using a PARK system XE 100E atomic force microscopy (AFM). The absorbance, transmittance and reflectance spectra of the films were measured using a Shimadzu UV-VIS-NIR 3600 spectrophotomer.

\section{Results and discussion}

The AFM images of pure $\mathrm{CdO}$ and $\mathrm{La}$ doped $\mathrm{CdO}$ films are shown in Fig. 1. The grain size and surface roughness values of the films are given in Table. It is observed that the particle size of $\mathrm{CdO}$ is decreased with increase in La-doping level. It can be seen in Fig. 1 that the surface roughness of the $\mathrm{CdO}$ film is changed with increase in La-doping level from 0 to $2 \%$. It is evaluated 


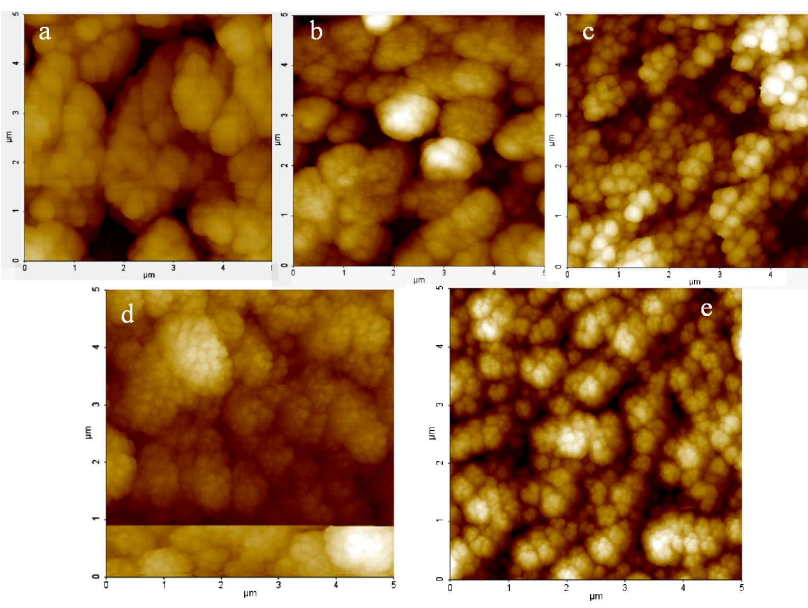

Fig. 1. AFM images of (a) pure CdO, (b) $0.1 \%$ La-doped CdO, (c) $0.5 \%$ La-doped CdO, (d) $1 \%$ La-doped $\mathrm{CdO}$ and (e) $2 \%$ La-doped CdO.

that the surface roughness of the films depends on the distribution of particles on surface of the films.

TABLE

The crystal grain size and surface roughness $R_{\mathrm{q}}$ values of the $\mathrm{CdO}$ and La doped $\mathrm{CdO}$ thin films.

\begin{tabular}{c|c|c|c}
\hline \hline Thin films & Grain size $[\mathrm{nm}]$ & $R_{\mathrm{q}}[\mathrm{nm}]$ & $E_{\mathrm{g}}[\mathrm{eV}]$ \\
\hline pure CdO & $350-250$ & 174.65 & 2.25 \\
$0.1 \% \mathrm{La}-\mathrm{CdO}$ & $250-200$ & 107.70 & 2.36 \\
$0.5 \% \mathrm{La}-\mathrm{CdO}$ & $150-105$ & $120-58$ & 2.40 \\
$1 \% \mathrm{La}-\mathrm{CdO}$ & $130-80$ & 207.16 & 2.28 \\
$2 \% \mathrm{La}-\mathrm{CdO}$ & $80-55$ & 90.43 & 2.31
\end{tabular}

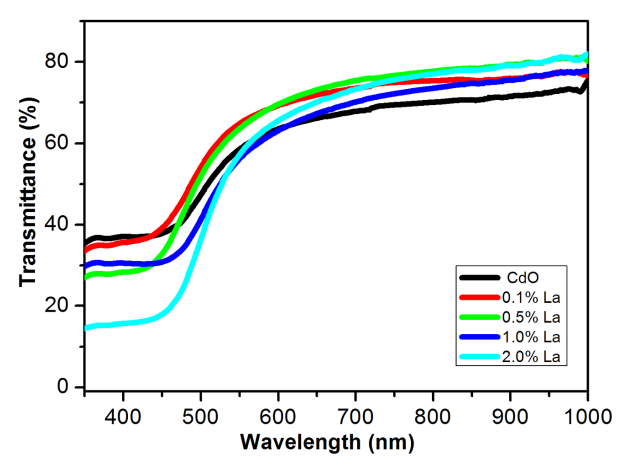

Fig. 2. Transmittance spectra of pure and La-doped CdO films.

The transmittance of pure $\mathrm{CdO}$ and La-doped $\mathrm{CdO}$ were measured in the range of 200 to $1000 \mathrm{~nm}$. Figure 2 shows that the La doping reduces the optical transmittance by up to $60 \%$ for $2 \%$ La doping $\mathrm{CdO}$ in the range of 300 to $450 \mathrm{~nm}$. This observation is consistent with results reported in Ref. [18]. However, La doping improves the optical transmittance by up to $15 \%$ for $2 \%$ La doping

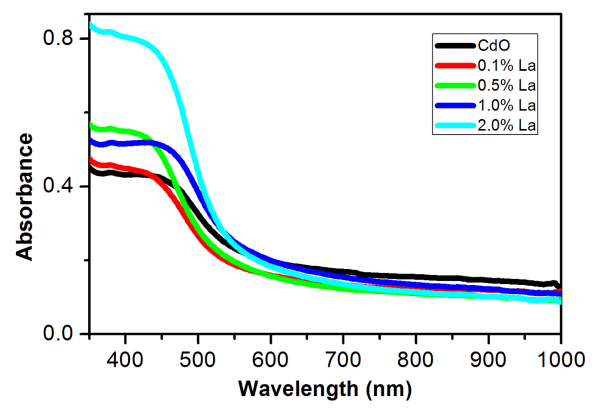

Fig. 3. Absorption spectra of pure and La-doped CdO films.

in the wavelength range from $550 \mathrm{~nm}$ to $1000 \mathrm{~nm}$ region. Absorption spectra of pure and La doped CdO films are shown in Fig. 3. As seen in Fig. 3, the CdO films exhibit an absorption edge, and it changes with La doping.

The optical band gap of the $\mathrm{CdO}$ films is calculated using the expression [19]:

$$
(\alpha h \nu)=B\left(h \nu-E_{\mathrm{g}}\right)^{n},
$$

where $B$ is constant, $\alpha\left[\mathrm{m}^{-1}\right]$ is the absorption coefficient, $\nu[\mathrm{Hz}]$ is the photon frequency and $E_{\mathrm{g}}[\mathrm{eV}]$ is the optical band gap. The parameter $n$ specifies the allowed direct $(n=1 / 2)$ and indirect $(n=2)$ transition in the electronic band structure. The band gap $E_{\mathrm{g}}$ was obtained from extrapolating the linear part of $(\alpha h \nu)^{2}$ vs. $h \nu$ plot to $\alpha=0$ as shown in Fig. 4. It was found that the La doping concentration affects the energy band gap $E_{\mathrm{g}}$. The direct band gap of pure $\mathrm{CdO}$ is $2.25 \mathrm{eV}$. This value is in good agreement with several reports [1]. The La doped $\mathrm{CdO}$ increases the band gap towards higher energy values which are in good agreement with the values reported by Dakhel and Ali-Mohamed [18]. The band gaps for $\mathrm{CdO}$ films were found to be $2.36,2.4,2.28$, and $2.31 \mathrm{eV}$ for $\mathrm{La}$

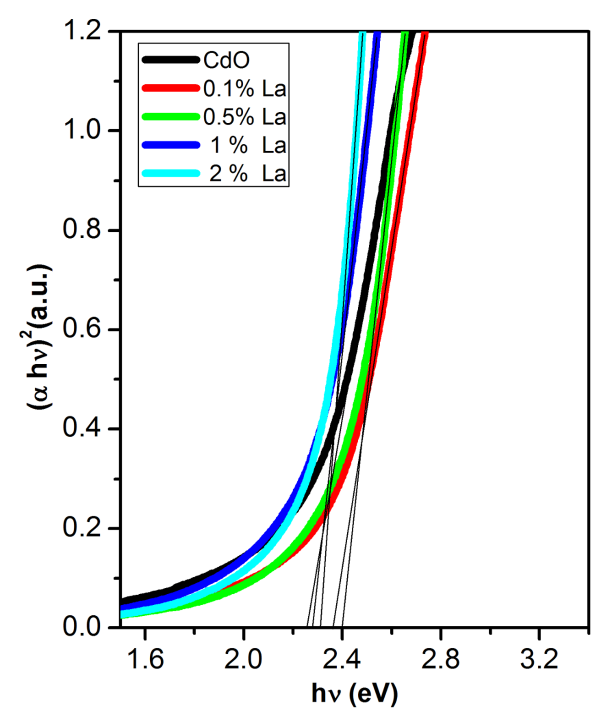

Fig. 4. Plots of $(\alpha h \nu)^{2}$ vs. $h \nu$ for pure $\mathrm{CdO}$ and La doped $\mathrm{CdO}$ films. 


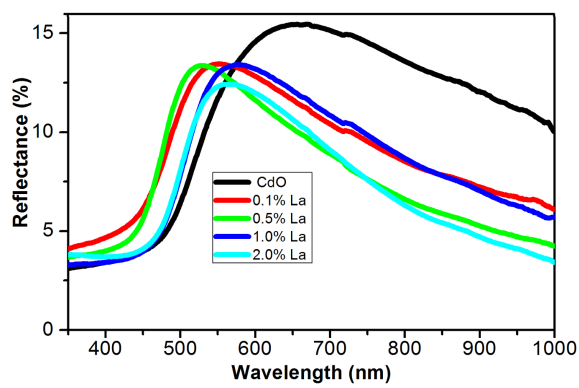

Fig. 5. Reflectance spectra of pure and La doped CdO films.

with $0.1,0.5,1$, and $2 \%$ doped $\mathrm{CdO}$, respectively. The change in optical band gap with La doping is due to $\mathrm{La}^{3+}$ ions incorporating into the crystalline structure. These ions occupy interstitial positions and in turn, a deformation is formed in the periodic crystal potential. The electrons are interacting with this potential and this interaction causes a change in the optical band gap.

The reflectance spectra of the undoped and La doped $\mathrm{CdO}$ films are shown in Fig. 5. It is observed that the average reflectance of $\mathrm{CdO}$ film is increased in the range of 200 to $500 \mathrm{~nm}$ and decreases from the range of 550 to $1000 \mathrm{~nm}$ with the increase in La doping level. The change in the reflectance of the films suggests that the refractive index of the $\mathrm{CdO}$ films is changed with La doping. The refractive index of the $\mathrm{CdO}$ film in the range of 550$1000 \mathrm{~nm}$ exhibits the lowest value for $2 \%$ La dopant, but the films exhibit the highest value for undoped $\mathrm{CdO}$ film. It is evaluated that the refractive index exhibits a normal dispersion behavior in 550-1000 $\mathrm{nm}$ range.

\section{Conclusions}

We have investigated the structural and optical properties of La doped $\mathrm{CdO}$ films with low concentration of La and synthesized by sol-gel method. The result of AFM studies for the surface of $\mathrm{CdO}$ films indicates that the crystal size of the $\mathrm{CdO}$ film can be modified by varying the La doping level. The films are formed from nanocluster consisting of nanoparticles. The size of nanocluster is controlled by La dopant. It was found that the band gap energy of $\mathrm{CdO}$ increase from 2.25 to $2.40 \mathrm{eV}$ with the increase of La content up to $0.5 \%$ in the film.

\section{Acknowledgments}

This work is supported by NPST Program by King Saudi University project number 10-NAN1197-02.

\section{References}

[1] N. Ueda, H. Maeda, H. Hosono, H. Kawazoe, J. Appl. Phys. 84, 6174 (1998).

[2] T.L. Chu, S.S. Chu, J. Electron Mater. 19, 1003 (1990).

[3] M. Ortega, G. Santana, A. Morales, Solid State Electron. 44, 1765 (2000).

[4] R.S. Mane, H.M. Pathan, C.D. Lokhande, S.H. Han, Solar Energy 80, 185 (2006).

[5] F. Yakuphanoglu, Appl. Surf. Sci. 257, 1413 (2010).

[6] R. Maity, K.K. Chattopadhyay, Sol. Energy Mater. Sol. Cells 90, 597 (2006).

[7] C. Aydın, H.M. El-Nasser, F. Yakuphanoglu, I.S. Yahia, M. Aksoy, J. Alloys Comp. 509, 854 (2011).

[8] R.K. Gupta, F. Yakuphanoglu, F.M. Amanullah, Physica E 43, 1666 (2011).

[9] A.A. Dakhel, Solar Energy 82, 513 (2008).

[10] I. Akyuz, S. Kose, E. Ketenci, V. Bilgin, F. Atay, J. Alloys Comp. 509, 1947 (2011).

[11] R.K. Gupta, Z. Serbetci, F. Yakuphanoglu, J. Alloys Comp. 515, 96 (2012).

[12] F. Dagdelen, Z. Serbetci, R.K. Gupta, F. Yakuphanoglu, Mater. Lett. 80, 127 (2012).

[13] C. Aydin, A. Omar, A.A. Al-Hartomy, F. AlGhamdi, I.S. Al-Hazmi, F. Yahia, F. El-Tantawy, J. Yakuphanoglu, Electroceram. 29, 155 (2012).

[14] A.A. Dakhel, Curr. Appl. Phys. 12, 1 (2012).

[15] M.M. Vijatović Petrović, J.D. Bobić, T. Ramoška, J. Banys, B.D. Stojanović, Mater. Character. 62 , 1000 (2011).

[16] F.D. Morrison, D.C. Sinclair, A.R. West, J. Appl. Phys. 86, 6355 (1999).

[17] C.Z. Zhao, S. Taylor, M. Werner, P.R. Chalker, R.T. Murray, J.M. Gaskell, A.C. Jones, J. Appl. Phys. 105, 044102 (2009).

[18] A.A. Dakhel, A.Y. Ali-Mohamed, J. Sol-Gel Sci. Technol. 44, 241 (2007).

[19] J.I. Pankove, Optical Processes in Semiconductors, Dover Publications, New York 1971. 